\title{
Receptiveness of Maintaining Dental Records for Forensic and Other Matters
}

\author{
AQIB SOHAIL ${ }^{1}$, NIGHAT ZAHID ${ }^{1}$, ANEELA AMJAD², FAREED UD DIN CHISHTI ${ }^{1}$, UZAIR ABU BAKAR ${ }^{1}$, FIZZAH ALI $^{1}$ \\ ${ }^{1}$ Lahore Medical \& Dental College, Lahore \\ ${ }^{2}$ Sharif Medical \& Dental College, Lahore \\ Correspondence to Dr. Nighat Zahid, Associate Professor of Oral \& Maxillofacial Surgery, Email: nighat.zahid@Imdc.edu.pk, Cell: \\ 03054109468
}

\begin{abstract}
Background: Dental records assume a significant part as these might be utilized in identification of dead or missing humans, as proof in court and in criminological dentistry as discoveries of posthumous assessments are contrasted with antemortem dental evidence that have been well-maintained.

Aim: To evaluate the awareness regarding significance of dental records and receptiveness of the practitioner toward maintenance in proper pattern.

Method: This cross sectional descriptive was carried out between September and December, 2019 at established dental institution of Lahore. A questionnaire containing 16 close ended question was formulated and distributed to all the participants. We seek approval from ethical committee of Lahore Medical \& Dental College. Statistics was investigated through SPSS version 20; Pearson correlation coefficient was utilized.

Results: A total of 350 dental practitioners took part in this study, statistics revealed that $68.3 \%$ were familiar with importance of maintaining records. Though $96 \%$ dental professionals record the full name, age and gender of patients, 94\% explore medical history, $78 \%$ record various developmental dental anomalies and $39 \%$ notice decayed, missed or filled teeth; but in general $55.4 \%$ percent maintain the patient-related correspondence. Amongst them $33.5 \%$ of dental professionals preserve the dental file, $40 \%$ percent conserve the radiographs, $29 \%$ photographs of the patients, and just $10 \%$ of the dentists preserve the casts. Duration of conserving dental records found inconstant; $40 \%$ sustain all the patient-related correspondence for a month or less, $21.20 \%$ for a half year, $18.4 \%$ for a year, $6.4 \%$ as long as 5 years and just $1 \%$ for around 10 years.

Conclusion: Information and receptiveness of maintaining records among the dental professionals of Lahore is inadequate, improvement can be accomplished by education and training.

Keywords: dental records, identification, forensic dentistry, patient chart.
\end{abstract}

\section{INTRODUCTION}

A dental record is an authoritative archive that contains all abstract and target data about the patient and it is in the ownership of the dental specialist. It contains the patient's historical backdrop of disease and related fundamental ailment, clinical assessment, dental diagrams, conclusion, the treatment done, and notes on ensuing follow-up ${ }^{1}$. A dental proforma gives data about the refinements of the apparent crowding of teeth present in the mouth, dental anomalies, teeth present or missing, restorative efforts, pathologies like caries, furcation inclusion, root pieces, and periodontal health ${ }^{2}$. The dental record likewise establishes radiographs, including skull and all-encompassing radiographs, CT study and treatment outlines, impressions, research facility, examination reports, clinical photos, consultancy and reference reports, composed notes, drug prescriptions, and patient identification data including dental replacement and implant labeling ${ }^{3}$. Any set of experiences or recognition of child exploitation or household maltreatment ought to be recorded properly ${ }^{4}$. These records play an important role in communication, identification of dead or missing, as evidence in court or to justify the claim submitted by insurance companies and to promote teaching and research ${ }^{5-7}$.

Received on 24-02-3031

Accepted on 07-07-2021
Forensic dentistry aids in identification of people who are visually distorted or within the absence of fingerprints due to devastating coincidences where bodies are completely disintegrated; as dental tissues are able to withstand prolonged decomposition additionally as high degrees of temperature, humidity and pressure ${ }^{8-10}$. This can be highly captivated with the ante mortem dental records, a post mortem dental record is compiled from the autopsy and accustomed compare the characteristics of a personal ${ }^{11}$. Forensic odontology has played important role in identification of humans and was also used to effectively recognize $80 \%$ of the Tsunami victims in South East Asia in December 2004 ${ }^{12-15}$.

Dental record is significant in light of the fact that it might be utilized as proof in court or in an administrative activity. An appropriately reported dental record can be utilized to counter an objection from patient, with regards to charges of carelessness, or to legitimize handling ${ }^{16}$. The Health Insurance Portability and Accountability Act (HIPAA) of 1996, has exaggerated the dental record for wellbeing and patient security ${ }^{17}$. Dental records are additionally proof of the work performed and could be important to get paid by insurance agencies. In the event that the outline does not legitimize the case presented, an insurance agency may reject installment or requested repayment. In these circumstances, insurance agencies could review the archives or even account to the concerned organization, maintaining great information avoids this surplus pressure. Each individual from the dental group is similarly 
answerable for recording appropriate realities about a patient's visit on the outline. Dental specialists ought to counsel their lawyer, preceding changing the records over to any of the strategies. Original records are never to be delivered, including radiographs, to any gathering. Regardless of how formal a request for the originals may seem, just duplicates should be sent ${ }^{18}$.

Collectively medical and monetary archives, drug and lab prescriptions must be sustained for about a decade afterward the completion of treatment; on account of a minor, these records must be saved until patient reaches adulthood, or whenever possible up to age of twenty-five years. Regarding orthodontic models, initial and final must be reserved for a period of five years; without preserving the transitional modles ${ }^{19}$.

A large portion of the organizations and dental expert of developing nations still save the records on paper because of nonavailability of gadgets at larger part territories, additionally they feel it is more convenient and modest technique. To store the records electronically consume fewer space when compare to paper records and more data can be protected for prolong time ${ }^{20}$. In case where it is difficult to preserve patient's files, medical reports and models; such stuff can be preserved by taking images. Electronic dental records also contribute to the capabilities of tele-dentistry. Tele-dentistry involves live video meetings and correspondence between dentist and patient using mobile electronics such as phone, tablet, and computer 21,22 .

The intention of this study is to appraise the information regarding the cruciality of dental records and approach of the dental experts toward possession of these records in proper instance.

\section{MATERIALS AND METHODS}

This cross-sectional descriptive study was carried out between September and December, 2019 at established dental institution of Lahore after approval from Ethical Committee. A questionnaire containing 16 close ended question was formulated and study was completely discussed with ethical and examination group of Lahore Medical \& Dental College; the inquiries were short recorded and selected precisely to feature our point. An ideal dental record report was accumulated and utilized as a correlation archive; this include inquiries regarding the age, gender, work experience, awareness, court witness, practice of keeping records, documents they preserved and mode of keeping those records. The dental professionals were visited on a solitary day after the endorsement from ethical boards of every one of these institutions. The questionnaire was delivered to all available dental professionals, confidentiality and anonymity of the members was guaranteed. Analysis of this investigation was carried out by using version 20 of SPSS; the Pearson correlation coefficient was applied; level of importance was set to $\mathrm{p} \leq 0.01$.

\section{RESULTS}

A total of 350 dental professionals from various recognized dental institutions of Lahore took part in this study. $139(39.71 \%)$ of our participants were males, $211(60.29 \%)$ were females. All the participants were in the age range of 26-51 years; with a mean age of 34 years. We grouped study populace into three types; there were 136(39\%) general dental surgeons, $112(32 \%)$ postgraduate residents and $102(29 \%)$ consultants. The participants were questioned about their information related to importance of maintaining records and their attitude towards it. Study displayed that approximately $51 \%$ of the general dental surgeons, $68 \%$ of the postgraduate residents and $91 \%$ of consultants were aware of maintaining records in regard that this information can be utilized; in identification of dead or missing humans, in court as an expert witness of suspect or victim of child abuse, domestic violence, rape, suicide (Table 1 ).

Receptiveness of sustaining the dental records in our study group found to increase with practice and accountability; the postgraduates were found more motivated toward keeping the records as compare to general dentists, study has showed $49 \%$ of general dental surgeons, $51 \%$ of postgraduate residents and $73 \%$ faculty sustain the records of their patients. As an entire $55 \%$ professionals maintained the patient related correspondence whereas $45 \%$ did not (Table 2 ).

Table 1: Awareness of significance of maintaining dental record

\begin{tabular}{|l|c|c|c|}
\hline Designation & \multicolumn{2}{|c|}{$\begin{array}{c}\text { Are you familiar with } \\
\text { significance of maintaining } \\
\text { dental records? }\end{array}$} & \multirow{2}{*}{ Total } \\
\cline { 2 - 3 } & Yes & No & \\
\hline $\begin{array}{l}\text { General Dental } \\
\text { Surgeons }\end{array}$ & $70(51.47 \%)$ & $66(48.53)$ & 136 \\
\hline $\begin{array}{l}\text { Postgraduate } \\
\text { Residents }\end{array}$ & $76(67.85 \%)$ & $36(32.15 \%)$ & 112 \\
\hline Consultants & $93(91.18 \%)$ & $11(8.82 \%)$ & 102 \\
\hline Total & $239(68.29 \%)$ & $111(31.71 \%)$ & 350 \\
\hline
\end{tabular}

Table 2: Maintenance of dental records

\begin{tabular}{|l|c|c|c|}
\hline \multirow{2}{*}{ Designation } & \multicolumn{2}{|c|}{$\begin{array}{c}\text { Do you maintain dental } \\
\text { records of your patients? }\end{array}$} & \multirow{2}{*}{ Total } \\
\cline { 2 - 3 } & Yes & No & \\
\hline $\begin{array}{l}\text { General Dental } \\
\text { Surgeons }\end{array}$ & $62(48.52 \%)$ & $74(51.475)$ & 136 \\
\hline $\begin{array}{l}\text { Postgraduate } \\
\text { Residents }\end{array}$ & $57(50.89 \%)$ & $55(49.11 \%)$ & 112 \\
\hline Consultants & $74(72.55 \%)$ & $28(27.45 \%)$ & 102 \\
\hline Total & $193(55.42 \%)$ & $157(44.56 \%)$ & 350 \\
\hline
\end{tabular}

In our investigation group who maintained records, $96 \%$ dental professionals record the full name, age and gender of patients, $58 \%$ record e-mail or postal addresses of the patients, half record patient's calling contact number. $74 \%$ about the recently done treatment techniques, $44 \%$ record marital status with number of youngsters, and just $28 \%$ notice about the socioeconomic status of the patient, $94 \%$ the professionals included in the study record, the various preexisting systemic ailments such as heart complaints, high or low blood pressure, diabetes, asthma, and allergy if any. Every one of them queried about the historical backdrop of pregnancy in female patients, $87 \%$ probe about the history of epilepsy, endocrine problems, congenital problems, liver or kidney diseases. Eighty-three percent notice the endorsed medicines in the dental record while $17 \%$ do not specify the recommended drugs in the document. 78 percent of dental experts record various 
developmental dental anomalies like microdontia, rotations, supernumerary teeth, congenitally absent teeth, abnormal shape, and diastema. Fifty percent register about torus maxillaris/mandibularis, only $39 \%$ mentioned they notice (DMFT) decayed, missed or filled teeth (Figure.1).

Regarding the preservation of data; only $34 \%$ of dental professionals preserve the dental file of the patients. Out of the complete dental professionals who keep up dental records, $83 \%$ of them record case history physically in preprinted structures though $6 \%$ of the professionals record it physically on a clear page, while the rest of $11 \%$ record the case history digitally. Regarding radiograph $40 \%$ percent dental practitioners conserve the radiographs whereas $18 \%$ preserve digital radiographs as a soft copy. $29 \%$ of the dentists told that they preserve soft copies of the photographs. Ninety percent of dentists did not preserve the casts and models after completion of treatment, and only $10 \%$ of the dentists preserve the casts after crown/bridge cementation and orthodontic treatment (Table 3).

At the point when we queried about the life span of conservation of dental records $; 40.09 \%$ of study populace used to save records for not exactly a month, $21.20 \%$ save for a half year, $18.4 \%$ for a year, $6.4 \%$ as long as 5 years and just $1 \%$ for around 10 years (Fig. 2).

Figure 1: Information stated on the dental file.

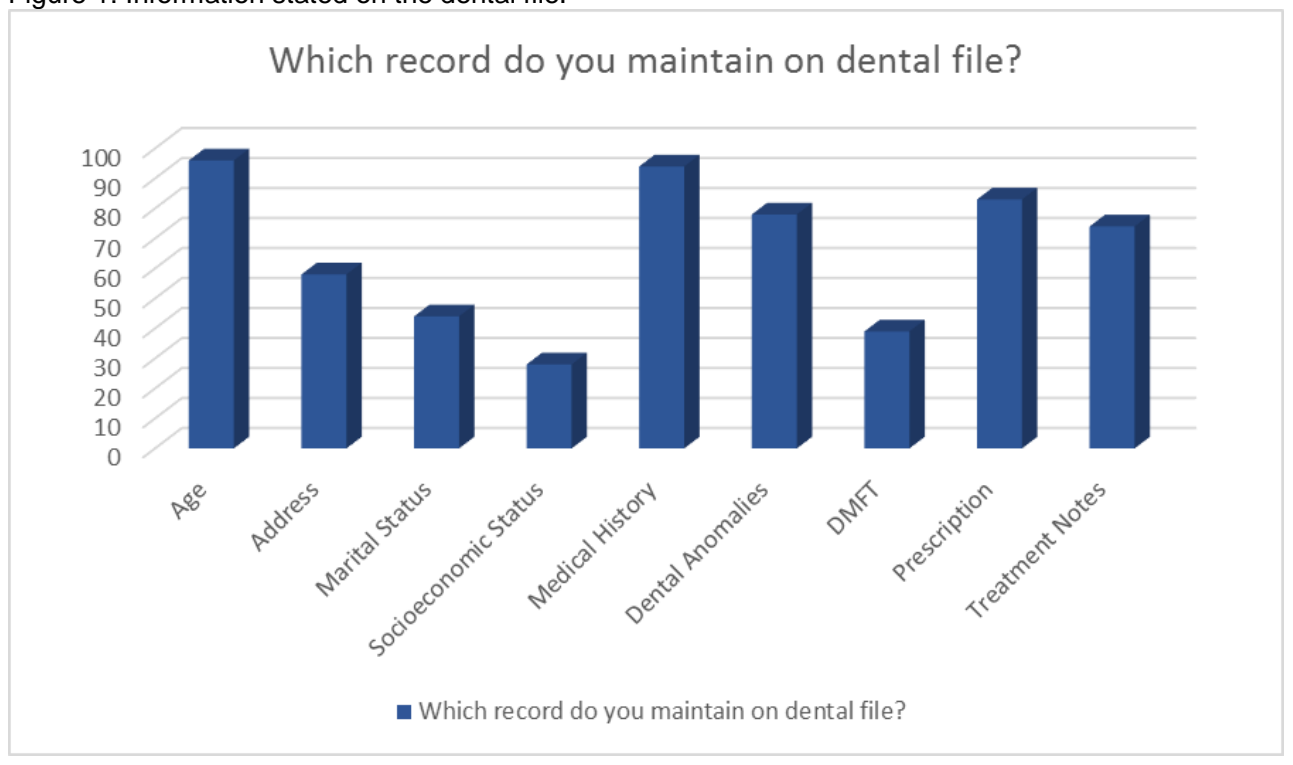

Fig. 2: Length of maintaining records

\begin{tabular}{|l|c|c|c|c|c|}
\hline \multirow{2}{*}{ Designation } & \multicolumn{3}{|c|}{ How do you maintain dental records of your patients? } & \multirow{2}{*}{ Total } \\
\cline { 2 - 6 } & Dental file & Radiograph & Photograph & Cast & \\
\hline General Dental Surgeons & 13 & 24 & 8 & 5 & 136 \\
\hline Postgraduate Residents & 52 & 56 & 42 & 14 & 112 \\
\hline Consultants & 49 & 60 & 53 & 16 & 102 \\
\hline Total & $144(33.57 \%)$ & $140(40 \%)$ & $103(29.42 \%)$ & $35(10 \%)$ & 350 \\
\hline
\end{tabular}

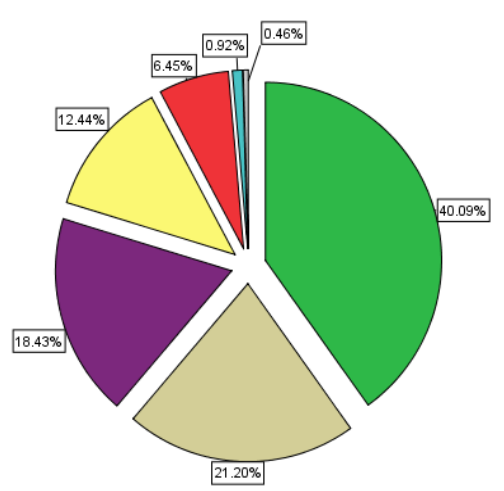

How long do you

Dless than 4 weeks

$1-6$ months
$6-12$ months

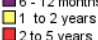

5 to 10 years

more than 10 years

\section{DISCUSSION}

Keeping up a dental record report as dental charts, radiographs, photos, impressions, casts and so on, is a moral and a legitimate commitment with respect to the dental professionals. These records assume a significant part as the dental record might be utilized in identification of dead or missing humans, as proof in court and in criminological dentistry as discoveries of posthumous assessments are contrasted and antemortem dental detections that have been conserved into the records.

This investigation was directed among the dental professionals of Lahore to survey their insight with respect to the significance of dental records and keeping them in authentic instance. Study has displayed that approximately $51 \%$ of the general dental surgeons, $68 \% \%$ of the postgraduate residents and $91 \%$ of consultants were aware of maintaining records 
Fifty five percent of practitioners mentioned that they conserve the dental records whereas forty five percent practitioners did not keep up any dental records of their patients. Receptiveness of sustaining the dental records in our study group found to increase with practice and accountability; the consultants found to be most particular towards preserving records $(73 \%) ; 51 \%$ of post graduate residents have maintained records, whereas general dental surgeons showed up the least attention (49\%).A past report completed by Preethi et al. derived that solitary $12 \%$ kept up a total dental record and $21 \%$ did not keep up any record, while $93 \%$ dental specialists did not save a record for more than 7 years ${ }^{23}$. Astekar et al. found that only $38 \%$ of dentists retain records whereas $62 \%$ did not maintain any record of the patients ${ }^{24}$.

The significance and estimation of radiographs should never be thought little of as they assume a significant function in recognition by getting positive identifiable proof, just as they assume a part in age assessment, by the quantity of teeth erupted ${ }^{25}$. Waleed et al. carried out a comparative study between students and dentists, and found out that $100 \%$ of students maintained intraoral periapical radiographs whereas $8 \%$ of students and $6 \%$ of dentists obtained bitewing radiographs ${ }^{26}$. In our survey we found that $35 \%$ practitioners retain the radiographs whereas $55 \%$ do not conserve the radiographs but $26 \%$ of them mentioned that they note the findings of the radiographs in the case history form which could help to correlate and compare antemortem and postmortem interpretations.

Photos are significant in the distinguishing proof of an individual outwardly as the Countess of Salisbury has been recognized outwardly by her gold dental replacement. Waleed et al found only $8 \%$ of dentists and $28 \%$ of students maintain photographs of the patient ${ }^{26}$. Shakira found that $100 \%$ dentists preserve the soft copy of photographs ${ }^{27}$. In our study $30 \%$ dentists mentioned that they took photographs for their patients; $20 \%$ for every case while $10 \%$ of dentists took photographs only for special or rare cases.

Cast and study models are extremely valuable in recognizing a person through rugoscopy; as each person on the planet has a novel example and is considered as a solid technique in posthumous cases. In this way, experiencing projects and study models can be truly important ${ }^{28}$. Waleed et al. observed $49 \%$ of students obtained cast and study models of their patients whereas only $21 \%$ of the dentists retrieved them ${ }^{26}$. In our case only $10 \%$ of dentists preserve the casts after crown/bridge cementation or orthodontic management till first follow-up whereas $90 \%$ of dentists did not.

Different particulars utilized in the study assist us with assessing the nature of record that the experts keep up. Through the review we discovered $95 \%$ of dental specialists use ink for record composing, $5 \%$ referenced the utilization of ink or pencil according to the accessibility during the register of the case history. Strangely, we additionally found that couple of dental specialists have begun keeping up records carefully in personal computers. It was seen through our overview that lone $11 \%$ professionals of Lahore recorded case history digitally. The attention to keeping up record digitally should be expanded as it is the most effortless route as to support for a more drawn out timeframe and requires less space too ${ }^{29}$.

In our investigation the life span of conserving dental records found inconstant $; 40.09 \%$ of study populace used to save records for not exactly a month, $21.20 \%$ save for a half year, $18.4 \%$ for a year, $6.4 \%$ as long as 5 years and just $1 \%$ for around 10 years. American Dental Association expressed that dormant dental records must be saved for in any event seven years and for a situation of youngsters keep up it until the time of twenty-eight years. ${ }^{30}$ In India $93 \%$ of the dentists retain their dental records for less than seven years ${ }^{31,32}$

Different inquires utilized in the survey assist us with assessing the nature of record that the experts keep up. Extra dental anomalies, for example, formative variation in the size, shape, and number of teeth like microdontia and turned teeth were referenced by $78 \%$ of the professionals. This can demonstrate as one of the significant antemortem rules in the support of record which would assume a significant function from the crime scene investigation perspective in the recognizable proof of the people in question ${ }^{33}$. We found that $70 \%$ of experts notice the chronic number of an implant; this is again a significant guideline as it can hold in the oral cavity for a broad term ${ }^{34}$. We likewise saw that there is no single framework followed for tooth numbering, and this could make an issue in future for uncovering the particulars of the patients' records or while counseling another expert ${ }^{35}$.

\section{CONCLUSION AND RECOMMENDATIONS}

This study revealed that the information and exercise regarding proper record maintenance among these study subjects is insufficient. More awareness is required to evaluate its potential use for the cases of forensic importance and its implication for identification of victims in mass disasters.

Dental practitioners should be skilled to keep great archives in future that would be precise for both treatment and dento-legitimate reasons. Charts and recording frameworks must be standardized; clear guidelines ought to specify from the dental experts in Pakistan for dental construal framework and having emphasis to implication.

Acknowledgment: We would like to offer recognition to the individuals who participated in the project for they spare time and to the staff of all the institution for their cooperation.

Conflict of interest: Authors have no conflict of interest Funding: None

\section{REFERENCES}

1. Shanbhag VL. Significance of Dental Records in Personal Identification in Forensic Sciences. J Forensic Sci Med 2016; 2:39-43.

2. Anamika G, Gaurav M, Hemant B, Chetan H, Ashish B. A revolution needs maintenance of dental records of patients by the dentists: a descriptive study J. Int. Soc. Prev. Community Dent 2016;6: 316-20.

3. Lawney M. For the Record. Understanding Patient Record keeping. N Y State Dent J. 1998; 64:34-43.

4. Arora KS, Bansal R. The use of dental records as a tool for the Unique Identification Authority of India in personal 
identification: A proposal. J Forensic Dent Sci 2018; 10:11922.

5. Anwar A, Sardar KP, Nasir S, Waqar SM. Knowledge, Attitude and Practice of Forensic Odontology among Graduates and Post Graduate Students at Dow University of Health Sciences (DUHS). JPDA 2016; 25(3):110-14.

6. Inadequate record keeping by dental practitioners. Aust Dent J. 2015; 60:497-502.

7. Viner MD, Robson J. Post-mortem forensic dental radiography - a review of current techniques and future developments. J Forensic Radiol Imag. 2017; 8:22-37.

8. G.S. Sarode, et al., Dental records of forensic odontological importance: maintenance pattern among dental practitioners of Pune city, J. Forensic Dent. Sci. 9 (2017) 48.

9. Akram S, Arif Z, Khan S, Tauhed S. Knowledge, awareness and practice of forensic odontology among dental practitioners in Karachi. PJMD 2019; 8(01):78-83.

10. Arif $M$, Qayyum R Shaikh Q Forensic Odontology and a Dental Specialist. Ann. Pak. Inst. Med. Sci. 2016; 12(4):244247.

11. Ata-Ali J, Ata-Ali F. Forensic dentistry in human identification: A review of the literature. J Clin Exp Dent 2014; 6:162-7.

12. Al-AzriAR, Harford J, James $\mathrm{H}$. Awareness of forensic odontology among dentists in Australia; are they keeping forensically valuable dental records? Aust Dent J 2015; 61:102-8.

13. Tsokos M, Lessig R, Grundmann $C$, et al. Experiences in tsunami victim identification. Int J Legal Med. $2006 ; 120: 185$ 187.

14. Cordner S, Ellingham STD. Two halves make a whole: both first responders and experts are needed for the management and identification of the dead in large disasters. Forensic Sci Int. 2017; 279:60-64.

15. Khalil MA., et al. "Human's dentition uses in criminal investigations". PODJ 2014;34(4): 743-747.

16. Lam JS, Simpson BK, Lau FH. Health Insurance Portability and Accountability Act Noncompliance in Patient Photograph Management in Plastic Surgery. Ann Plast Surg. 2019 May;82(5):486-492.

17. Berry MD, Thomson RA. Healthcare Reform. Enforcement and Compliance. Issue Brief Health Policy Track Serv. 2018 Dec 24; 2018:1-38.

18. Charangowda BK. Dental records: An overview. J Forensic Dent Sci. 2010;2(1):5-10.

19. Sidek YH, Martins JT. Perceived critical success factors of electronic health record system implementation in a dental clinic context: An organizational management perspective. Int J Med Inform 2017; 107: 88-100.

20. Maserat E, Davoodi S, Mohammadzadeh Z. Analysis of strengths, weaknesses, opportunities, and threats of electronic dental and oral records in clinics of School of
Dentistry, Tehran University of Medical Sciences, Iran: A qualitative study. J Oral Health Oral Epidemiol 2020; 9(1): 2431.

21. Manica S. A new website to aid the interpretation of antemortem dental records: www. internationaldentalcharts. org. J Forensic Odontostomatol. 2014; 32:1-7.

22. Nuzzolese E, Marcario V, Di Vella G. Incorporation of radio frequency identification tag in dentures to facilitate recognition and forensic human identification. Open Dent J 2010; 4:33-6.

23. Preethi S, Einstein A, Sivapathasundharam B. Awareness of forensic odontology among dental practitioners in Chennai: A knowledge, attitude, practice study. J Forensic Dent Sci. 2011; 3:63-6.

24. Astekar M, Saawarn S, Ramesh G, Saawarn N. Maintaining dental records: Are we ready for forensic needs? J Forensic Dent Sci. 2011; 3:52-7.

25. Middleton A, Alminyah A, Apostol MA, et al. Forensic odontology radiography and imaging in disaster victim identification. J Forensic Radiol Imag. 2016; 6:28-30

26. Waleed P, Baba F, Alsulami S, Tarakji B. Importance of Dental Records in Forensic Dental Identification. Acta Informatica Medica 2015;23(1):49-52.

27. Sarode GS, Sarode SC, Choudhary S, Patil S, Anand R, Vyas $\mathrm{H}$. Dental records of forensic odontological importance: Maintenance pattern among dental practitioners of Pune city. J Forensic Dent Sci. 2017;9(1):48.

28. Shetty, Divya et al. Assessment of palatal rugae pattern and their reproducibility for application in forensic analysis. J Forensic Dent Sci 2013;5(2):106-9.

29. Asgari I. Development an Electronic Oral Health Record application for educational dental setting. J Edu Health Promot 2018;7:124

30. American Academy of Pediatric Dentistry. Clinical Affairs Committee - Infant Oral Health Subcommittee. Guideline on infant oral health care. Pediatr Dent. 2012; 34:148-52.

31. Kalyan A, Clark RK, Radford DR. Denture identification marking should be standard practice. Br Dent J. 2014; 216:615-617.

32. V. Vannala, et al., Forensic odontology in India key milestones and missed opportunities, Eur. J. Forensic Sci. 4 (2017) 1.

33. M. Rajshekar, T. Mithun, J. Idiculla, M. Tennant, Developmental anomalies of teeth and their applications in Forensic Odontology, Eur. J. Forensic Sci. 3 (2015) 39

34. Mishra SK, Mahajan H, Sakorikar R, Jain A. Role of prosthodontist in forensic odontology. A literature review. J Forensic Dent Sci 2014;6:154-9.

35. Peck S, Peck L. Tooth numbering progress. Angle Orthod. 1996;66:83-84 